\title{
Métodos de extração e concentrações no efeito inseticida de Ruta graveolens L., Artemisia verlotorum Lamotte e Petiveria alliacea L. a Diabrotica speciosa Germar
}

\author{
BARBOSA, F.S.; LEITE, G.L.D.*; MARTINS, E.R.; GUANABENS, R.E.M.; SILVA, F.W.S. \\ UFMG, Insetário G.W.G. de Moraes, Instituto de Ciências Agrárias, Av. Universitária, n. 1000, B. Universitário, Cx. \\ Postal 135, CEP: 39404-006, Montes Claros, MG *e-mail:gldleite@ufmg.br
}

\begin{abstract}
RESUMO: O objetivo deste trabalho foi determinar o melhor método de extração e concentração para Ruta graveolens L. (Rutaceae), Artemisia verlotorum Lamotte (Asteraceae) e Petiveria alliacea L. (Phytolaccaceae) quanto ao efeito inseticida a Diabrotica speciosa Germar (Coleoptera: Chrysomelidae). Os extratos que utilizaram óleo de soja comercial, pelo menos como um dos solventes, apresentaram maior mortalidade de $D$. speciosa em suas testemunhas (solvente $=$ óleo), nas três plantas estudadas, em relação às suas concentrações. O extrato aquoso de $R$. graveolens, a $5 \%$ de concentração, apresentou maior mortalidade corrigida de $D$. speciosa (32,5\%) que os extratos de $A$. verlotorumem água (10\% de concentração) $(20,3 \%)$ e $P$. alliaceaem álcool etílico (2\% de concentração) (12,5\%). O método de extração com água é simples, sendo passível de utilização por pequenos agricultores. A R. graveolens é planta facilmente cultivada, sendo, portanto, boa alternativa de controle dessa praga.
\end{abstract}

Palavras-chave: plantas medicinais, besouros desfolhadores, controle alternativo

\begin{abstract}
Extraction methods and concentrations for the insecticidal effect of Ruta graveolens L., Artemisia verlotorum Lamotte, and Petiveria alliacea L. against Diabrotica speciosa Germar. The aim of this work was to determine the best extraction method and concentration for Ruta graveolens L. (Rutaceae), Artemisia verlotorum Lamotte (Asteraceae) and Petiveria alliacea L. (Phytolaccaceae) concerning their insecticidal effect against Diabrotica speciosa Germar (Coleoptera: Chrysomelidae). Extracts using commercial soybean oil as at least one of the solvents resulted in higher $D$. speciosa mortality in controls (solvent $=$ oil) of the three studied plants, relative to their treatment concentrations. $R$. graveolens extract in water, at $5 \%$ concentration, showed higher $D$. speciosa corrected mortality (32.5\%) than $A$. verlotiorum extracts in water (10\% concentration) $(20.3 \%)$ and $P$. alliacea in ethanol ( $2 \%$ concentration) $(12.5 \%)$. The extraction method with water is simple and can be used by small farmers. $R$. graveolens is an easily cultivated plant and constitutes, therefore, a good alternative to control this plague.
\end{abstract}

Key words: medicinal plants, defoliating beetles, alternative control

\section{INTRODUÇÃO}

Atualmente as monoculturas ocupam vastas áreas do planeta. Essas culturas, muitas vezes, são atacadas por insetos herbívoros, cujas populações ocasionam danos econômicos, se tornando pragas. O principal método de controle às pragas é o químico, o que ocasiona, em geral, contaminação do ambiente, redução de inimigos naturais, intoxicações do produtor rural e do consumidor final e elevação dos custos de produção (Altieri et al., 2003).

Entretanto, o uso sistemático de inseticidas tem selecionado populações de pragas resistentes, sendo necessário buscar novos princípios ativos. Uma das fontes de princípios ativos são as plantas, que durante o processo evolutivo, desenvolveram mecanismos para se protegerem do ataque de herbívoros, como os metabólicos secundários produzidos como resposta direta a um estímulo ambiental (Martins et al., 2005). Esses princípios ativos podem ser sintetizados, tornando-se novos inseticidas químicos, ou usados na forma de extratos. As vantagens de se utilizar extratos de plantas é que são foto-instáveis, reduzindo o impacto no ambiente, mais baratos e de fácil utilização, em geral, por agricultores (Rodriguez \& Vendramim, 1996; Cespedes et al., 2000; Martines, 2001).

Dentre as plantas passíveis de utilização

Recebido para publicação em 19/05/2007

Aceito para publicação em 20/06/2009 
tem-se a Ruta graveolens L. (Rutaceae), Artemisia verlotorum Lamotte (Asteraceae) e Petiveria alliacea L. (Phytolaccaceae) por apresentarem efeitos deletérios sobre algumas pragas e microorganismos e de fácil cultivo ou aquisição (Mendes et al., 1984; Berger et al., 1998; Cáceres et al., 1998; Almeida et al., 1999; Benevides et al., 2001; Echevarría \& Idavoy, 2001; Lopes-Martins et al., 2002; Lapenna et al., 2003; Martins et al., 2005; Leite et al., 2006). Entretanto, é preciso avançar com os estudos, não somente com outras pragas, mas também buscando alternativas baratas de extração, menos tóxicos e de fácil preparo para os agricultores, ou seja, sem o uso de extratores como o metanol ou hexano (MoralesCifuentes et al., 2001).
Entre as pragas mais comuns das diversas plantas cultivadas tem-se a Diabrotica speciosa Germar (Coleoptera: Chrysomelidae), alimentando-se de folhas, brotações novas, e frutos, reduzindo a produtividade. As larvas consomem o sistema radicular das plantas, diminuindo sua massa e, como conseqüência, a massa da parte aérea, altura das plantas e produção (Cardoso et al., 2002; Azeredo et al., 2004; Pereira et al., 2005). Contudo, não há estudos de efeito de extratos de plantas sobre essa importante praga.

Portanto, o objetivo deste trabalho foi determinar o melhor método de extração e concentração para $R$. graveolens, $A$. verlotorume $P$. alliacea quanto ao efeito inseticida a $D$. speciosa.

TABELA1. Métodos de extração.

\begin{tabular}{|c|c|c|c|}
\hline Extrato & $\begin{array}{c}\text { Folhas (\%) } \\
\text { (Peso em relação ao } \\
\text { volume) }\end{array}$ & $\begin{array}{l}\text { Solvente }(\%) \\
\quad \text { (volume) }\end{array}$ & Preparo \\
\hline 1 & $\begin{array}{l}20 \% \text { do peso fresco } \\
\text { da folha }(100 \mathrm{~g})\end{array}$ & $\begin{array}{|lr|}60 \% \text { de } & \text { água } \\
\text { destilada } & (300 \\
\mathrm{mL})+40 \% & \text { de } \\
\text { óleo de } & \text { soja } \\
\text { comercial } & (200 \\
\mathrm{mL}) & \end{array}$ & $\begin{array}{l}\text { Triturou-se em liquidificador industrial para } \\
\text { homogeneização e, em seguida, aquecido à } 50^{\circ} \mathrm{C} \\
\text { por } 15 \text { minutos. As misturas foram mantidas em } \\
\text { recipientes de vidro âmbar com tampa por } 24 \mathrm{~h} \\
\text { para completar o processo de extração. Após esse } \\
\text { período, foram filtradas, e acondicionadas, }\end{array}$ \\
\hline 2 & $\begin{array}{l}10 \% \text { do peso fresco } \\
\text { da folha }(50 \mathrm{~g})\end{array}$ & $\begin{array}{l}60 \% \text { de água } \\
\text { destilada }(300 \\
\mathrm{mL})+20 \% \text { de } \\
\text { óleo vegetal }(100 \\
\mathrm{mL})+20 \% \text { de } \\
\text { álcool etílico }(100 \\
\mathrm{mL})\end{array}$ & novamente em frascos de vidro âmbar. \\
\hline 3 & $\begin{array}{l}40 \% \text { do peso fresco } \\
\text { da folha }(100 \mathrm{~g})\end{array}$ & $\begin{array}{|lr|}90 \% \text { de } & \text { água } \\
\text { destilada } & (225 \\
\mathrm{mL})+10 \% & \text { de } \\
\text { óleo de } & \text { soja } \\
\text { comercial } & (25 \\
\mathrm{mL}) & \end{array}$ & $\begin{array}{l}\text { As folhas, juntamente com água destilada, foram } \\
\text { trituradas em liquidificador industrial para } \\
\text { homogeneização, em seguida adicionou-se o óleo } \\
\text { e aqueceu-se em banho-maria por } 15 \text { minutos. }\end{array}$ \\
\hline 4 & $\begin{array}{l}20 \% \text { do peso fresco } \\
\text { da folha }(30 \mathrm{~g})\end{array}$ & $\begin{array}{|lr|}100 \% \text { de } & \text { água } \\
\text { destilada } & (150 \\
\mathrm{mL}) & \end{array}$ & $\begin{array}{l}\text { Triturou-se em liquidificador industrial até a } \\
\text { homogeneização, em seguida, aqueceu-se a } \\
\text { mistura até o início da ebulição, esperou-se pelo } \\
\text { esfriamento da mistura e, posteriormente, } \\
\text { procedeu-se à filtração e acondicionamento em } \\
\text { vidro âmbar. }\end{array}$ \\
\hline 5 & $\begin{array}{l}20 \% \text { do peso fresco } \\
\text { da folha }(50 \mathrm{~g})\end{array}$ & $\begin{array}{l}100 \% \text { de álcool } \\
\text { etílico hidratado } \\
\text { comercial } \quad(250 \\
\mathrm{mL})\end{array}$ & $\begin{array}{l}\text { Triturou-se em liquidificador industrial, } \\
\text { acondicionando em recipientes de vidro âmbar } \\
\text { com tampa por } 48 \mathrm{~h} \text { para completar o processo de } \\
\text { extração. Após esse período, o extrato foi filtrado } \\
\text { e acondicionado em frasco de vidro âmbar. }\end{array}$ \\
\hline 6 & $\begin{array}{l}20 \% \text { do seu peso } \\
\text { seco }(20 \mathrm{~g})\end{array}$ & $\begin{array}{l}100 \% \text { de óleo de } \\
\text { sojar comercial } \\
(100 \mathrm{~mL})\end{array}$ & $\begin{array}{l}\text { As folhas foram secas em estufa à } 40^{\circ} \mathrm{C} \text { por } 48 \mathrm{~h} \text {, } \\
\text { em seguida moídas até obtenção do pó, } \\
\text { acondicionando em frasco de vidro âmbar } \\
\text { juntamente com o óleo. A mistura foi levada a } \\
\text { aquecimento em banho-maria por } 2 \mathrm{~h} \text {. Após o } \\
\text { resfriamento, o extrato foi filtrado e acondicionado } \\
\text { em frasco de vidro âmbar. }\end{array}$ \\
\hline
\end{tabular}




\section{MATERIAL E MÉTODO}

O experimento foi conduzido no Instituto de Ciências Agrárias da Universidade Federal de Minas Gerais (ICA/UFMG) em agosto de 2006. O delineamento foi inteiramente casualizado com quatro repetições, sendo que cada repetição consistiu de uma placa de Petri de vidro (10 x 2 $\mathrm{cm}$ ) com 10 adultos de $D$. speciosa, coletados em lavoura de feijão orgânico, não sexados e de idade desconhecida, acondicionados em estufa incubadora a $25^{\circ} \mathrm{C}$, avaliando-se a mortalidade após 24 e 48 horas.

As plantas de $R$. graveolens, A. verlotorum e $P$. alliacea foram cultivadas organicamente no Horto Medicinal do ICA/UFMG em Latossolo Distrófico Vermelho de textura média. Os extratos foram elaborados mediante a possibilidade de disponibilizarem compostos polares ou apolares que pudessem ser extraídos de cada planta medicinal, usou-se, então, óleo de soja comercial como extrator de compostos apolares; água e álcool etílico comercial $\left(95,5^{\circ} \mathrm{GL}\right)$, como extratores de compostos polares (Barbosa, 2000).

Testaram-se seis métodos de extração para cada planta (Tabela 1). Após a obtenção de cada extrato das plantas em estudo, testaram-se quatro dosagens de 2, 5, 10 e $15 \%$ do volume de cada extrato. Um folíolo apical de feijão foi imerso, por dois segundos, na concentração referente a cada extrato das plantas estudadas. Esse folíolo foi mantido na sombra e ao ar livre por duas horas até a evaporação do excesso de água. Após isso, foi acondicionado em placa de petri de $10 \mathrm{~cm}$ de diâmetro com 10 adultos de $D$. speciosa, avaliando a mortalidade após 24 e 48 horas. Como testemunhas foram utilizados dois procedimentos, um no qual se acondicionava os 10 adultos do inseto em folíolo de feijão e outro com folíolo de feijão imerso no solvente utilizado no processo de extração, sendo utilizado o mesmo procedimento de secagem e de repetições dos supracitados. Os extratos foram utilizados nos testes de mortalidade após 24 a 48 horas de confeccionados.

Os dados foram submetidos à análise de variância, ao teste de média Scott-Knott e a análise de regressão linear (somente na concentração e forma de extração ideal), todos a $5 \%$ de probabilidade de erro. $\mathrm{Na}$ avaliação do melhor método de extração e da concentração para cada planta, a mortalidade não foi corrigida pela testemunha, já que poderia ocorrer maior mortalidade na testemunha em relação às concentrações, resultando em mortalidade negativa. Após a escolha da melhor concentração e melhor forma de extração para as plantas, foi então utilizada a correção da mortalidade.

\section{RESULTADO E DISCUSSÃO}

Os extratos das três plantas estudadas que utilizaram óleo de soja comercial, pelo menos como um dos solventes, apresentaram maiores mortalidades de $D$. speciosanas testemunhas (solvente $=$ óleo) $\mathrm{em}$ relação às concentrações, tanto em 24 como em 48 horas de avaliação (Figuras 1, 2 e 3).

Devido a esses resultados, o óleo de cozinha não é recomendado como solvente, pois as concentrações que apresentaram maiores mortalidades deveram-se ao solvente e não às plantas e, nestas concentrações, acarretariam sérios problemas de fitotoxidade às plantas ou diminuição das trocas gasosas $\left(\mathrm{CO}_{2} / \mathrm{O}_{2}\right)$ nos estômatos, dificultando a fotossíntese em condições de campo, como observado para óleo mineral (Koller et al., 1999).

Os extratos de $R$. graveolens, que utilizaram água ou álcool como solventes, não diferiram das testemunhas (solventes), nas diferentes concentrações, quanto às mortalidades de $D$. speciosa após 24 horas de exposição. Entretanto, após 48 horas, as maiores mortalidades foram observadas nas concentrações 5 e $10 \%$ utilizando água como solvente (Figura 1). As diferentes concentrações não diferiram, entre si, após 48 horas, mas apresentaram maiores mortalidades de $D$. speciosa comparado à testemunha solvente - álcool etílico (Figura 1).

As diferentes concentrações não diferiram, entre si, após 48 horas, mas apresentaram maiores mortalidades de $D$. speciosa comparada à testemunha solvente - álcool etílico (Figura 1). A partir desses resultados preliminares, confrontaram-se as melhores concentrações utilizando água ( $5 \%$ de concentração) eálcool etilico (2\%, por gastar menos planta no preparo) como solventes, apresentando maior mortalidade dos adultos dessa praga com o primeiro solvente (Figura 4).

À extração com água $5 \%$ de $R$. graveolens ocasionou mortalidade, por meio de ingestão e contato, em torno de $30 \%$ de adultos de $D$. speciosa em 48h (Figura 4). O efeito inseticida de $R$. graveolens sobre os insetos $D$. speciosa, neste trabalho, Sitophilus spp. (Coleoptera: Curculionidae) (Almeida et al., 1999) e Ctenocephalides canis (Curtis) (Siphonaptera: Pulicidae) (Leite et al., 2006) devese, provavelmente, as cumarinas, aos flavonóides e aos alcalóides presentes nas folhas (Martins et al., 2005). Esses compostos são notados em outras plantas, apresentando efeitos deletérios sobre Bemisia tabaci (Genn.) (Hemiptera: Aleyrodidae) (Cavalcante et al., 2006) e Anticarsia gemmatalis (Hübner) (Lepidoptera: Noctuidae) (Gazooni et al., 1997).

Os extratos de $A$. verlotorum, que utilizaram água como solvente não diferiram da testemunha, tanto em 24 quanto em 48 horas de exposição, quanto à mortalidade de $D$. speciosa. Entretanto, na concentração de $15 \%$ em etanol, após 24 h, resultou 


\section{Ruta graveolens}
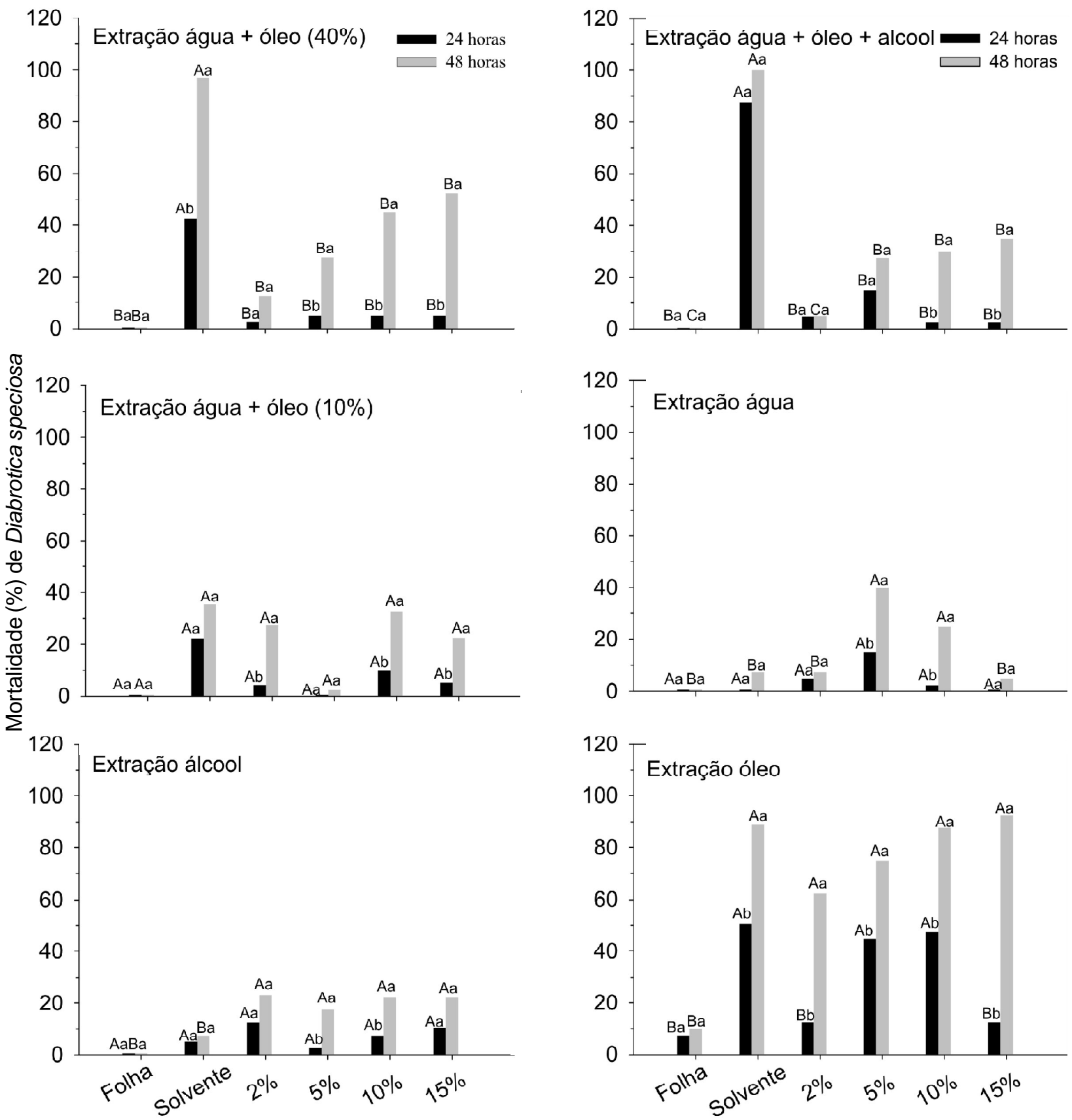

Tratamentos

FIGURA 1. Efeito de solvente e concentração de extrações da planta Ruta graveolens sobre a percentagem de mortalidade de adultos de Diabrotica speciosa em 24 e 48 horas. Médias seguidas de mesma letra maiúscula, comparando tratamentos, e minúscula, comparando as horas, não diferem, entre si, pelo teste de Scott-Knott a $\mathrm{p}<0,05$.

em maior mortalidade da praga em comparação com os demais tratamentos (Figura 2). Compararam-se, então, o extrato $10 \%$ em água com o extrato $15 \%$ em álcool, apresentando, o primeiro extrato, maior mortalidade de $D$. speciosa (Figura 4), resultando, após 48 horas, em torno de $20 \%$ de mortalidade
(Figura 4). O efeito inseticida de $A$. verlotorum sobre $D$. speciosa se deve, provavelmente, aos sesquiterpenos e as lactonas presentes em suas folhas (Geissman, 1970; Kelsey \& Shafizadeh, 1979). Esses compostos secundários também apresentaram efeito sobre Biomphalaria glabrata (Say) (Mollusca: 


\section{Artemisia verlotorum}
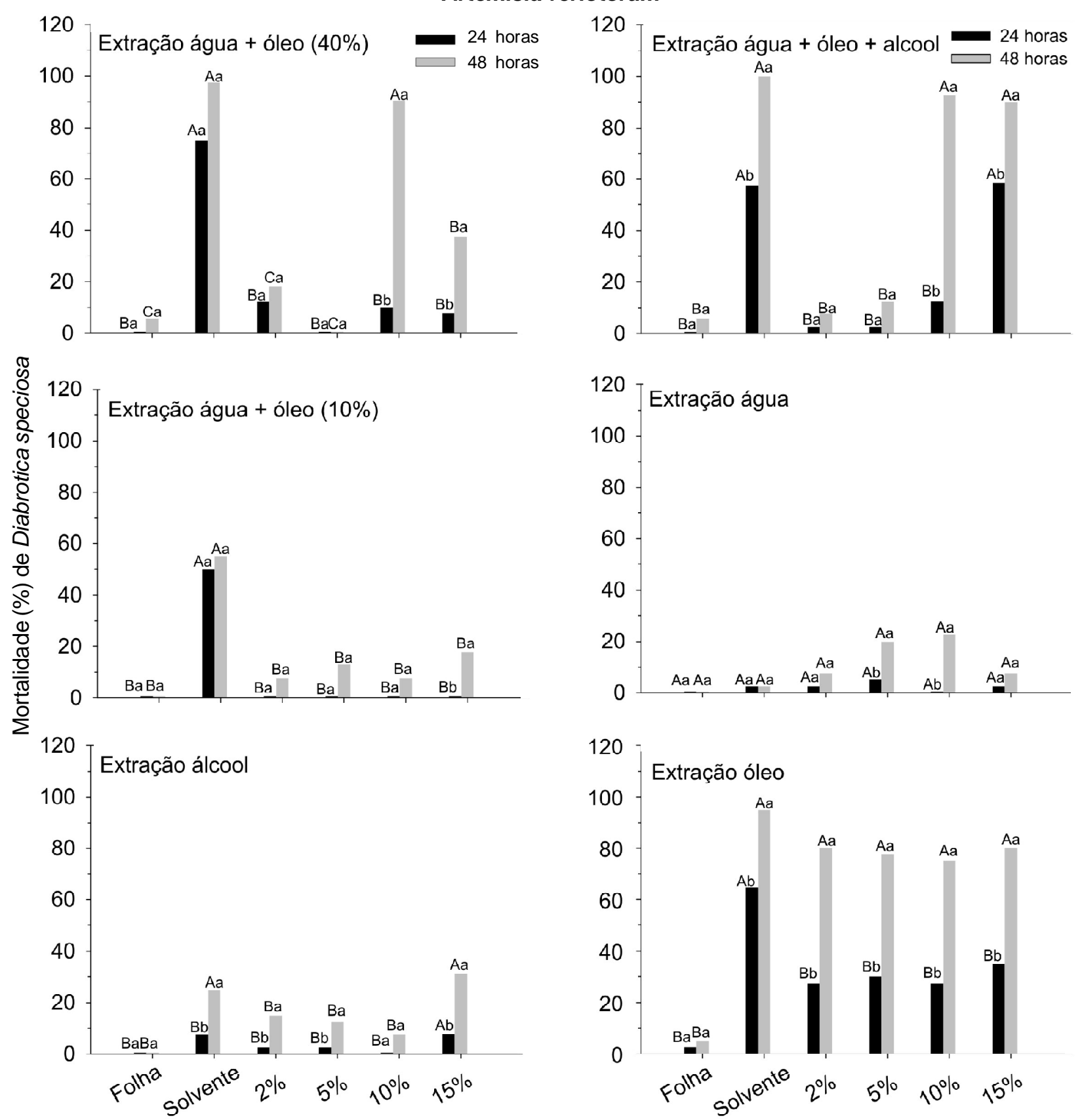

Tratamentos

FIGURA2. Efeito de solvente e concentração de extrações da planta Artemisia verlotorum sobre a percentagem de mortalidade de adultos de Diabrotica speciosa em 24 e 48 horas. Médias seguidas de mesma letra maiúscula, comparando tratamentos, e minúscula, comparando as horas, não diferem, entre si, pelo teste de Scott-Knott a $p<0,05$.

Planorbidae) (Mendes et al., 1984) e Spodoptera littoralis (Boisduval) (Lepidoptera: Noctuidae) (Viegas Júnior, 2003).

Tanto nos períodos de 24 e 48 horas de exposição, as diferentes concentrações de $P$. alliacea, utilizando água ou álcool como solventes, não diferiram da testemunha, quanto à mortalidade de $D$. speciosa (Figura 3). Comparou-se, então, o extrato $10 \%$ em água com o extrato $2 \%$ em etanol, apresentando maior mortalidade de $D$. speciosa o último extrato (Figura 4), resultando, após $48 \mathrm{~h}$, cerca de $15 \%$ de mortalidade desta praga (Figura 4). Essa 


\section{Petiveria alliacea}
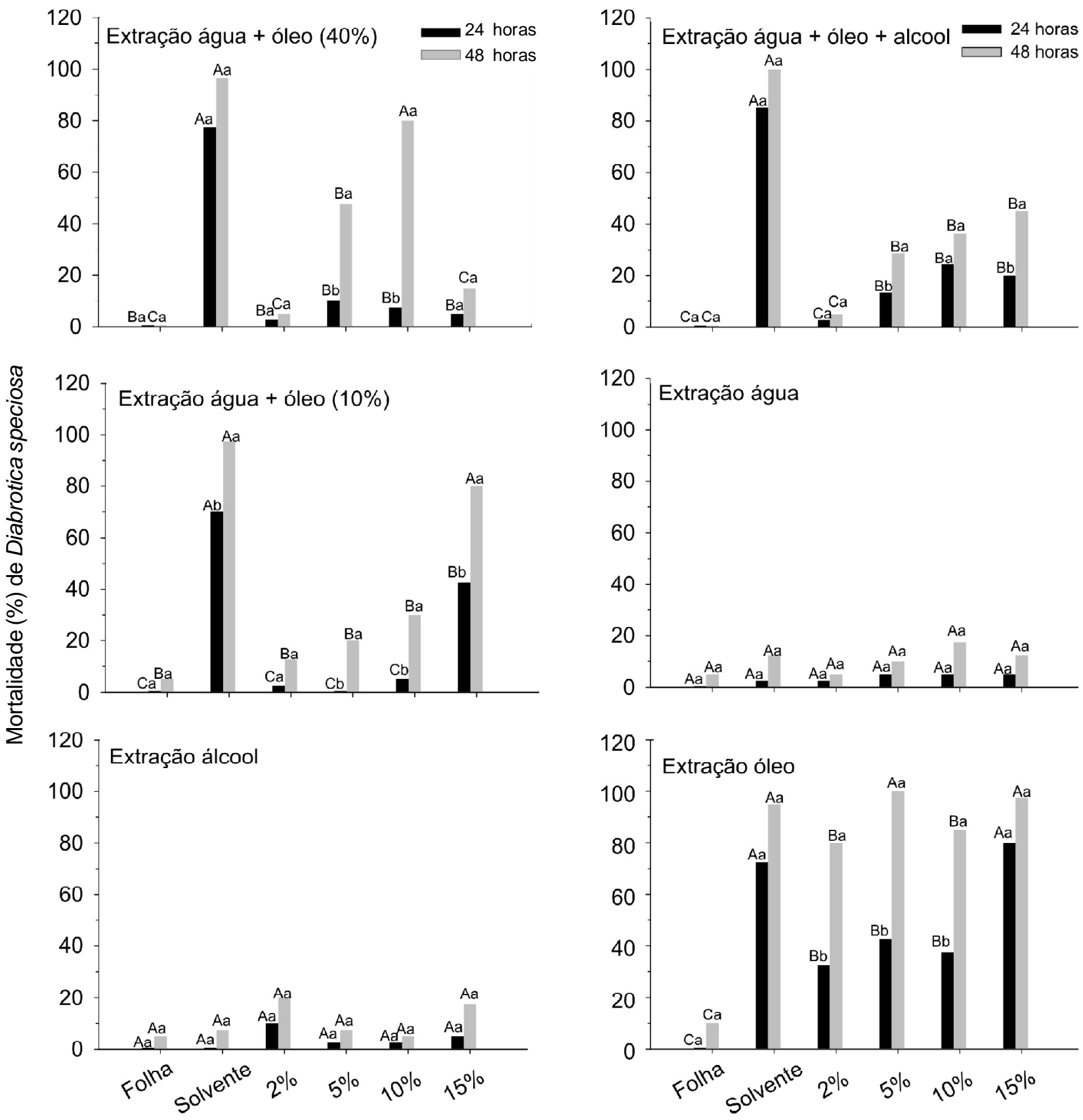

Tratamentos

FIGURA 3. Efeito de solvente e concentração de extrações da planta Petiveria alliacea sobre a percentagem de mortalidade de adultos de Diabrotica speciosa em 24 e 48 horas. Médias seguidas de mesma letra maiúscula, comparando tratamentos, e minúscula, comparando as horas, não diferem, entre si, pelo teste de Scott-Knott a $\mathrm{p}<0,05$.

planta possui nas folhas, cumarinas, triterpenos, flavonóides, aminoácidos (Benevides et al., 2001), óleo essencial, petiverina, ácido resinoso (LopesMartins et al., 2002), apresentando estes compostos efeitos negativos sobre Oligonychus ilicis (McGregor) (Acari: Tetranychidae), Iphiseiodes zuluagai(Denmark
\& Muma) (Acari: Phytoseiidae) (Martinez, 2002; Mourão et al., 2004), Aedes aegypti (Culicidae) (Trevisan et al., 2006), Trypanosoma cruzi (Cruz) (Kinetoplastidae: Tripanosomatina) (Berger et al., 1998; Cáceres et al., 1998), Giardia lamblia (Kunstler) (Diplomonadida: Hexamitidae) (Echevarría \& Idavoy, 


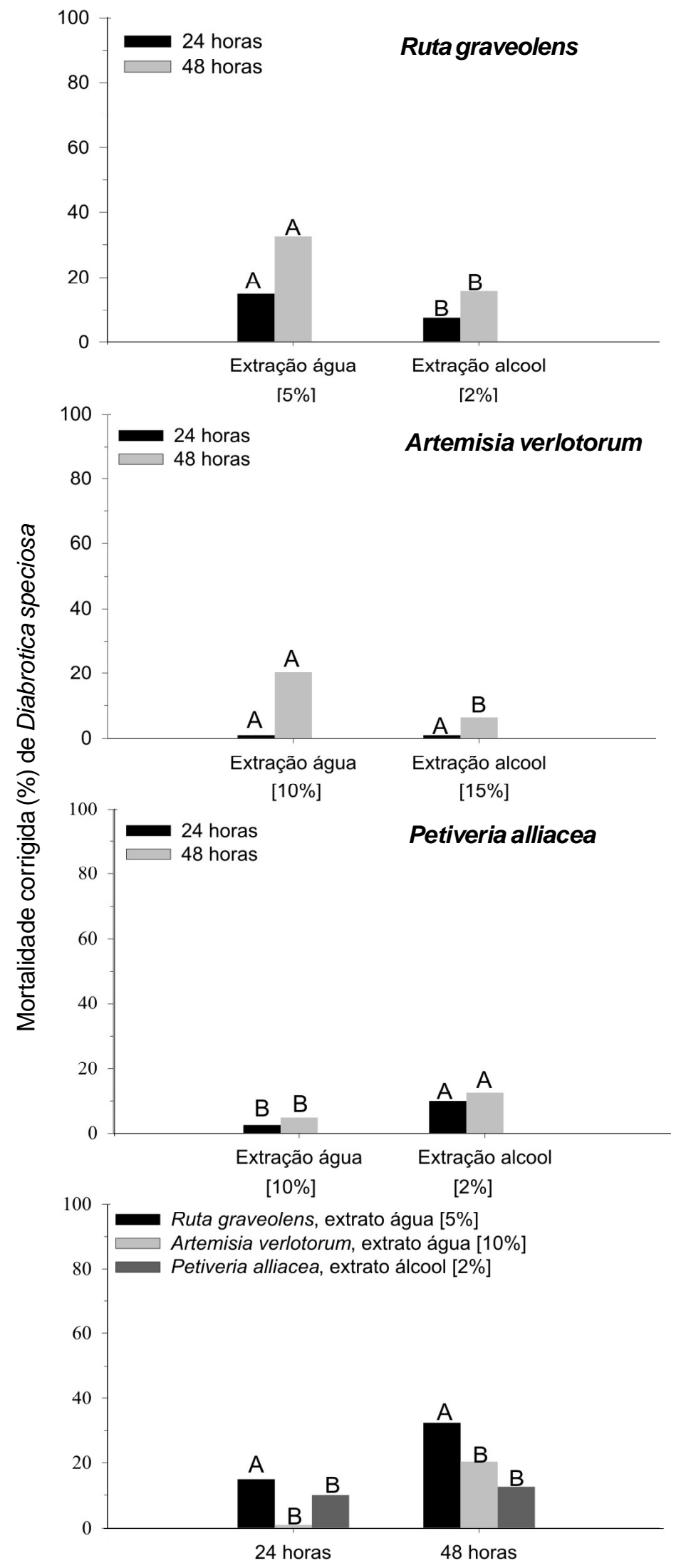

FIGURA 4. Comparação entre as melhores extrações, concentrações e plantas quanto à mortalidade corrigida de Diabrotica speciosa. Médias seguidas de mesma letra não diferem, entre si, entre grupos de histogramas, pelo teste de Scott-Knott a $p<0,05$.

Rev. Bras. Pl. Med., Botucatu, v.11, n.3, p.221-229, 2009. 
2001) e atividade antimicrobiana (Lapenna et al., 2003).

O extrato aquoso de $R$. graveolens ( $5 \%$ de concentração), apresentou maior mortalidade de $D$. speciosa, nos diferentes tempos de exposição, que os extratos de $A$. verlotorum em água (10\% de concentração) e $P$. alliacea em álcool (2\% de concentração) (Figura 4). Para matar 50 e $99 \%$ dos adultos de $D$. speciosa, seriam necessários $19,26 \%$ e $39,02 \%$ de concentração do extrato aquoso de $R$. graveolens $\left(\mathrm{y}=2,24+2,48 \mathrm{x} ; \mathrm{R}^{2}=0,61\right)$ contra $23,45 \%$ e $46,67 \%$ de $A$. verlotorumem água (48 h) (y $\left.=0,532,11 x ; R^{2}=0,44\right)$ e $51,90 \%$ e $103,47 \%$ de $P$. alliacea em etanol (48 h) $\left(y=0,70+0,95 x, R^{2}=\right.$ $0,52)$, respectivamente.

Provavelmente o extrato aquoso (5\%) de $R$. graveolens extraiu substâncias que não foram extraídas dos quais continham etanol.Outra possibilidade foi o modo de preparo, talvez disponibilizando maior quantidade dos princípios ativos inseticidas (Lehninger et al., 2000). Esse extrato aquoso de $R$. graveolens apresentou mortalidade de $D$. speciosa próximo ao obtido com o inseticida thiamethoxam, que matou em torno de $50 \%$ (Calafiori \& Barbieri, 2001).

De forma geral, o extrato aquoso de $R$. graveolens, na concentração de $5 \%$, apresenta efeito inseticida satisfatório sobre adultos de $D$. speciosa, sendo o método de extração aquoso simples e barato, passível de utilização pelos agricultores.

\section{AGRADECIMENTO}

À Coordenação de Aperfeiçoamento de Pessoal de Nível Superior - CAPES, pela concessão da bolsa de mestrado, ao CNPq e a FAPEMIG pelo suporte financeiro.

\section{REFERÊNCIA}

ALMEIDA, F.A.C.; GOLDFARB, A.C.; GOUVEIA, J.P.G. Avaliação de extratos vegetais e métodos de aplicação no controle de Sitophilus spp. Revista Brasileira de Produtos Agroindustriais, v.1, n.1, p.13-20, 1999.

ALTIERI, M.A.; SILVA, E.N.; NICHOLLS, C.I. O papel da biodiversidade no manejo de pragas. Ribeirão Preto: Holos, 2003. 226p.

AZEREDO, E.H.; LIMA, E.; CASSINO, P.C.R. Impacto dos nutrientes $\mathrm{N}$ e $\mathrm{K}$ e de açúcares solúveis sobre populações de Diabrotica speciosa (Germar) (Coleoptera, Chrysomelidae) e Agrotis ipsilon (Hüfnagel) (Lepidoptera, Noctuidae) na cultura da batata, Solanum tuberosum L. (Solanaceae). Revista Brasileira de Entomologia, v.48, n.1, p.105-13, 2004.

BARBOSA, L.C.A. Química orgânica: uma introdução para as ciências agrárias e biológicas. Viçosa: UFV, 2000. 354p.

BENEVIDES, P.J.C. et al. Antifungal polysulphides from
Petiveria alliacea L. Phytochemistry, v.57, n.5, p.743-7, 2001.

BERGER, I. et al. Plants used in Guatemala for the treatment of protozoal infections II. Activity of extracts and fractions of five Guatemalan plants against Trypanosoma cruzi. Journal of Ethnopharmacology, v.62, n.2, p.10715, 1998

CÁCERES, A. et al. Plants used in Guatemala for the treatment of protozoal infections. I. Screening of activity to bacteria, fungi and American trypanosomes of 13 native plants. Journal of Ethnopharmacology, v.62, n.3, p.195202, 1998

CALAFIORI, M.H.; BARBIERI, A.A. Effects of seed treatment with insecticide on the germination, nutrients, nodulation, yield and pest control in bean (Phaseolus vulgaris L.) culture. Revista Ecossistema, v.26, n.1, p.97-104, 2001

CARDOSO, A.M.; CIVIDANES, F.J.; NATALE, W. Influência da adubação fosfatada-potássica na ocorrência de pragas na cultura da soja. Neotropical Entomology, v.31, n.3, p.441-4, 2002.

CAVALCANTE, G.M.; MOREIRA, A.F.C.; VASCONCELOS, S.D. Potencialidade inseticida de extratos aquosos de essências florestais sobre mosca-branca. Pesquisa Agropecuária Brasileira, v.41, n.1, p.9-14, 2006.

CESPEDES, C.L. et al. Growth inhibitory effects on fall armyworm Spodoptera frugiperda of some limonoids isolated from Cedrela spp. (Meliaceae). Journal of Agricultural and Food Chemistry, v.48, n.5, p.1903-8, 2000.

ECHEVARRÍA, A.; IDAVOY, D.T. Efecto de um extrato de Petiveria alliacea lin sobre el crescimento de Giárdia lamblia in vitro. Revista Cubana Médica Militar, v.30, n.3, p.161-5, 2001.

GAZZONI, D.L.; HÜLSMEYER, A.; HOFFMANNCAMPO, C.B. Efeito de diferentes doses de rutina e de quercetina na biologia de Anticarsia gemmatalis Hübner, 1818 (Lep., Noctuidae). Pesquisa Agropecuária Brasileira, v.32, n.7, p.673-81, 1997. GEISSMAN, T.A. Sesquiterpene lactones of Artemisia$A$. verlotorum and $A$. vulgaris. Phytochemistry, v.9, n.11, p.2377-81, 1970.

KELSEY, R.G.; SHAFIZADEH, F. Sesquiterpene lactones and systematics of the genus Artemisia. Phytochemistry, v.18, n.10, p.1591-611, 1979.

KOLLER, O.C.; SOBRINHO, F.F.; SCHWARZ, S.F. Frutificação precoce de laranjeiras 'monte parnaso' com anelagem e pulverizações de ácido giberélico e óleo mineral. Pesquisa Agropecuária Brasileira, v.34, n.1, p.63-8, 1999.

LAPENNA, M.E.A. et al. Actividad bactericida y fungicida de algunas plantas utilizadas en la medicina tradicional venezolana. Revista del Instituto Nacional de Higiene Rafael Rangel, v.34, n.1, p.6-9, 2003.

LEHNINGER, A.L.; NELSON, D.L.; COX, M.M. Princípios de bioquímica. São Paulo: SARVIER, 2000. 839p.

LEITE, G.L.D. et al. Efeito de boldo chinês, do sabão de côco e da cipermetrina na mortalidade de pulgas em cachorro doméstico. Revista Brasileira de Plantas Medicinais, v.8, n.3, p.96-8, 2006.

LOPES-MARTINS, R.A.B. et al. The anti-Inflammatory and analgesic effects of a crude extract of Petiveria alliacea L. (Phytolaccaceae). Phytomedicine, v.9, n.3, 
p.245-8, 2002.

MARTINES, S.S. The use of plants with insecticidal and repellent properties in pest control. Londrina: Instituto Agronômico do Paraná, 2001. 4p.

MARTINEZ, S.S. O nim Azadirachta indica: natureza, usos múltiplos, produção. Londrina: Instituto Agronômico do Paraná, 2002. 142p.

MARTINS, A.G. et al. Levantamento etnobotânico de plantas medicinais, alimentares e tóxicas da llha do Combu, Município de Belém, Estado do Pará, Brasil. Revista Brasileira de Farmácia, v.86, n.1, p.21-30, 2005. MENDES, N.M. et al. Ensaios preliminares em laboratório para verificar a ação moluscicida de algumas espécies da flora brasileira. Revista Saúde Pública, v.18, n.5, p.348-54, 1984.

MORALES-CIFUENTES, C. et al. Neuropharmacological profile of ethnomedicinal plants of Guatemala. Journal of Ethnopharmacology, v.76, n.3, p.223-8, 2001.

MOURAO, S.A. et al. Selectivity of neem extracts
(Azadirachta indica A. Juss.) to the predatory Mite Iphiseiodes zuluagai (Denmark \& Muma) (Acari: Phytoseiidae). Neotropical Entomology, v.33, n.5, p.6137, 2004.

PEREIRA, T.; VENTURA, M.U.; MARQUES, F.A. Comportamento de larvas de Diabrotica speciosa (Coleoptera: Chrysomelidae) em resposta ao $\mathrm{CO}_{2}$ e a plântulas de espécies cultivadas. Ciência Rural, v.35, n.5, p.981-5, 2005.

RODRIGUES, C.H.; VENDRAMIM, J.D. Toxicidad de extractos acuosos de Meliaceae en Spodoptera frugiperda (Lepidoptera: Noctuidae). Manejo Integrado de Plagas y Agroecología, v.42, p.14-22, 1996.

TREVISAN, M.T.S. et al. Atividades larvicida e anticolinesterásica de plantas do gênero Kalanchoe. Química Nova, v.29, n.3, p.415-8, 2006.

VIEGAS JÚNIOR, C. Terpenos com atividade inseticida: uma alternativa para o controle químico de insetos. Química Nova, v.26, n.3, p.390-400, 2003. 


\title{
Germinação de sementes de sete espécies medicinais nativas do sul do Brasil
}

\author{
FERREIRA, A.G. ${ }^{1 *}$; ROSA, S.G.T. ${ }^{2}$ \\ Universidade Federal do Rio Grande do Sul, Caixa postal 15015, CEP. 91501-970 Porto Alegre/RS/Brasil \\ *ferreira@pq.cnpq.br, maytenus@terra.com.br
}

\begin{abstract}
RESUMO: Foram verificadas as condições ambientais de temperatura e de luz para germinação de diásporos de Borreria verticillata, Cayponia martiana, Echinodorus grandiflorus, Ocimum selloi, Plantago australis, Polygonum hydropiperoidese Waltheria douradinha. A germinação foi efetuada em placas de petri usando como substrato agar $1 \%$ ou em placas de gerbox com areia, em câmaras $\mathrm{BOD}$, nas temperaturas constantes de 10 e $15^{\circ} \mathrm{C}$ na ausência de luz ou nas temperaturas de 20, 25, 30 e 35ㅇ $\mathrm{C}$ na ausência ou presença de luz branca. Foram usadas ainda, temperaturas alternantes de $10-20^{\circ} \mathrm{C}, 15^{-25^{\circ}} \mathrm{C}, 20-30^{\circ} \mathrm{C}, 25-35^{\circ} \mathrm{C}$, sendo a temperatura mais alta, de cada par, com presença de luz por 9 horas. $B$. verticillata, $E$. grandiflorus e $P$. australis se mostraram com sementes fotoblásticas positivas, enquanto $O$. selloi comportou-se como fotoblástica positiva relativa. C. martiana e $W$. douradinha foram classificadas como afotoblásticas. $P$. hydropiperoides revelou possuir sementes termo-dependentes de temperaturas variáveis obrigatórias, enquanto nas demais espécies, a germinação em temperaturas variáveis ou constantes teve desempenho similar.
\end{abstract}

Palavras-chave: Borreria verticillata, Cayponia martiana, Echinodorus grandiflorus, Ocimum selloi, Plantago australis, P. hydropiperoides, W. douradinha

\begin{abstract}
Seed germination in seven medicinal species native to the south of Brazil. Environmental conditions of temperature and light were verified for diaspore germination in Borreria verticillata, Cayaponia martiana, Echinodorus grandiflorus, Ocimum selloi, Plantago australis, Polygonum hydropiperoides and Waltheria douradinha. Germination was carried out in Petri dishes, using $1 \%$ agar as substrate, or in gerbox containing sand, which were placed into BOD chambers at constant temperatures of 10 and $15^{\circ} \mathrm{C}$ in the absence of light or at $20,25,30$ and $35^{\circ} \mathrm{C}$ in the absence or presence of white light. Alternate temperatures of $10-20^{\circ} \mathrm{C}, 15-25^{\circ} \mathrm{C}, 20-30^{\circ} \mathrm{C}, 25^{-}$ $35^{\circ} \mathrm{C}$ were also tested, as well as the highest temperature in the presence of light during 9 hours/ day. B. verticillata, E. grandiflorus and $P$. australis showed positive photoblastic seeds, whereas $O$. selloiseeds behaved as relative positive. C. martiana and $W$. douradinha seeds were classified as non-photoblastic. P. hydropiperoides seeds were obligatorily dependent on variable temperatures, whereas in the remaining species, germination at variable or constant temperatures was similar. Não mexer no Abstract

Key words: Borreria verticillata, Cayponia martiana, Echinodorus grandiflorus, Ocimum selloi, Plantago australis, P. hydropiperoides, W. douradinha
\end{abstract}

\section{INTRODUÇÃO}

OBrasil abriga uma enorme biodiversidade distribuída por vários biomas e ecossistemas (Silva et al., 2006). A flora é rica em espécies nativas com princípios medicinas ativas e, as quais são largamente utilizadas na medicina popular, sendo que a maioria delas é usada de forma extrativista. À medida que cresce a ocupação humana com uso de novas áreas, esta pressão destrutiva aumenta (Rosa \& Ferreira, 2001). A disponibilização de informações sobre a propagação de espécies medicinais facilitará aos agricultores o cultivo destas plantas, favorecendo o mercado informal de erveiros e os pequenos e médios laboratórios farmacêuticos dedicados à produção de medicamentos de origem vegetal (Farias, 1999).

A propagação de plantas medicinais pode ser efetuada por via assexuada, em alguns casos, ou sexuada, representada pela germinação de sementes (Rosa \& Ferreira, 2001). A luz e a temperatura, além da água e oxigênio, são fatores ambientais de maior importância no fenômeno de

Recebido para publicação em 21/02/2008

Aceito para publicação em 19/02/2009 